hours; conditions of service and employment; equality and empowerment of women; disadvantageous sections of the society; social security. Each category was analysed using the search engine 'occupational safety and health' or 'occupational health and safety'. The Labour Rules under Labour Act were excluded as those are varied state to state. Since the study used data available in public domain and no human participants were involved it did not require ethics committee approval.

Results After extraction and analysis of all documents it was identified that the comprehensive safety and health statutes for regulating OSH at work places exist only in respect of the four sectors: the Factories Act, 1948; the Mines Act, 1952; Dock Workers Act, 1986; the Building and Other Construction Workers Act, 1996. There is no separate entity of legislation under the framework of OSH.

Discussion Although it is enshrined in the Constitution and the Legislature of India, the traditional concepts of OSH prevailing in the country is a far cry from the objectives of the ILO and international standards for OSH. Being a signatory participant for Convention 187 India has to comply with $\mathrm{OSH}$ in near future.

\section{RISKS AND MANAGEMENT OF AIRBORNE MERCURY LEVELS AT ARTISANAL GOLD PROCESSING SHOPS IN THE PERUVIAN AMAZON}

Jack Caravanos. Clinical Professor, Global Environmental Health, New York University, College of Global Public Health

\subsection{6/oemed-2018-ICOHabstracts.907}

Gold mining using the mercury amalgamation process continues to present serious community and occupational exposure problems throughout the world. It is now estimated that $30 \%$ of all processed gold is produced using mercury amalgamation with over 10 million people involved in artisanal and small scale gold mining. In Peru there has been a $400 \%$ increase in the ASGM activities and is ranked 5 th in worldwide gold production. It is estimated that one out of 28 people in Peru are associated with artisanal gold mining with Madre de Dios, an Amazonian State in Peru, accounting for $70 \%$ of mined gold. worker paper presents the results of mercury vapour area air sampling during the amalgam burning processing step where $\mathrm{Hg} / \mathrm{Au}$ amalgam is heated and the mercury driven off as a vapour phase. Small-scale artisanal gold miners often do not have the equipment to burn off the mercury from the amalgam and resort to local shops for this service. These Compra de Oro shops can be found in villages along the Interoceanic Highway traversing Madre de Dios. A total of 16 Gold Shops were sampled in 5 villages along the Interoceanic Highway in Madre de Dios. In almost all cases, the worker exposure levels exceeded internationally accepted health standards. Results of workplace sampling will be presented as well as a discussion of efforts and challenges in managing occupational health risks in small-scale artisanal enterprises in low and middleincome countries.

\section{THE ANALYSIS OF HEALTH ASSISTANCE FOR PREVENTION OF MENTAL AND PHYSICAL DISORDERS OF THE EMPLOYEES DISPATCHED TO MEDICALLY INSUFFICIENT COUNTRIES}

Hiroo Kaito, Hiromi Kuroishi, Toshitaka Yokoya, Kayo Kitahara, Yasuo Fukizawa. Mitsubishi Hitachi Power Systems, Itd, Yokohama, Japan

\subsection{6/oemed-2018-ICOHabstracts.908}

Introduction Doing EPC business at developing countries often confronts the health gap, so we understand it with an urgent problem that how the occupational health staffs should support the health of the employees working overseas. Fortunately we could analyse our experiences and draw methodology for this problem solution. We herein report our ideas.

Methods Health education, medical checkup including mental health examination, establishing medical overseas conveyance route with the help of assistance service are the basic techniques, besides that, we conduct medical patrol as an internal occupational health team in order to acquire the latest medical information through local medical institution and embassy doctor visit. We deliver unique health information leaflets including the mental health precaution digitally every month.

Result Joint medical patrol with the outside medical assistance company was useful for knowing and decreasing the hygiene, health gap. Through the original communication news which is delivering periodically as healthcare information to all employees outside, we are grading up the mental self-care power of workers. And assigning occupational health doctor periodically to the sites has got us the excellent reputation for original health assistance.

Discussion As much as work location is developing countries, the health gap leads to uneasiness. So the determination of urgent overseas medical conveyance route is indispensable to EPC business in risk management. The combination patrol investigation tied-up with the medical assistance company is important component of effective solutions for decreasing the uneasiness. To improve medical gap, besides local patrol visit by the occupational health staffs, newly-devised original health information of ours which delivered through digital communication technology is a unique technique to improve each person's self-care (resilience) power. Our original designed health care system so far obtained good evaluation and definitely leads to the precaution of employees' mental and physical disorders.

\section{OCCUPATIONAL HEALTH MONITORING - AUTOMATION OF THE RISK BASED OCCUPATIONAL HEALTH MEDICAL SURVEILLANCE PROGRAMME}

${ }^{1} \mathrm{~T}$ Nherera, ${ }^{2} \mathrm{~B}$ Masuku. 'BOC Zimbabwe (Pty) Ltd, Harare, Zimbabwe; ' University of Zimbabwe, Harare, Zimbabwe

\subsection{6/oemed-2018-ICOHabstracts.909}

Introduction Employees are exposed to occupational health hazards and are in need of medical surveillance to prevent ill health. Organisations carry out health risk assessments and these help anticipate the presence of health hazards. Hygiene surveys then confirm their presence and magnitude. 